\title{
Role of ocular matrix metalloproteinases in peripheral ulcerative keratitis
}

\author{
V A Smith, H B Hoh, D L Easty
}

\begin{abstract}
Aim-Peripheral ulcerative keratitis (PUK) is an ocular manifestation of rheumatoid arthritis and other similar systemic diseases. The purpose of this inquiry was to investigate the involvement of matrix metalloproteinases (MMPs) in the induction and/or maintenance of PUK.

Methods-Substrate gel electrophoresis was used to characterise the MMP activities secreted by primary cultures of keratocytes derived from normal and perforated pathological corneal specimens, and those present in tears of normal subjects and patients with PUK. Substrate specificity and the in vivo activity status of the secreted MMPs was assessed by SDS-polyacrylamide gel electrophoresis of standard collagens incubated in the presence or absence of the various enzyme preparations.
\end{abstract}

Results-In addition to MMP-2 of $M_{r}$ 66000 , cultured keratocytes derived from perforated corneas of patients with PUK abnormally produce the MMP-2 of apparent $M_{r} 62000$. Other MMPs and in particular MMP-9 of $M_{r} 92000$, also occur in the tears of these patients. Their visualisation on substrate polyacrylamide gels correlated with clinical manifestations of disease activity; during periods of disease quiescence they were barely detectable. The steroid prednisolone, frequently used in systemic therapy, had no effect on the in vitro activity of MMP-2, or on its production by cultured corneal keratocytes. Although the in vitro activity of MMP-2 was inhibited by both $\mathrm{Cu}^{2+}$ and $\mathrm{Zn}^{2+}, \mathrm{Cu}^{2+}$ apparently induced the keratocytes to produce activated enzyme and $\mathrm{Zn}^{2+}$ irreversibly inhibited their production of MMP-2.

Conclusion-Overexpression of corneal MMP-2 and tear film MMP-9 are characteristic features of patients with PUK and their activation may be a crucial facet of disease initiation or progression. Although effective in systemic therapy for PUK, prednisolone had no direct control over corneal MMP-2 production or activity. $\mathrm{Zn}^{2+}$ on the other hand inhibited both MMP-2 production and MMP-2 activity and may, therefore, be of therapeutic value if suitably formulated and used in conjunction with systemic steroid treatment. (Brf Ophthalmol 1999;83:1376-1383)

Peripheral ulcerative keratitis (PUK) is a chronic, progressive ocular manifestation of rheumatoid arthritis and other similar systemic diseases. Although the lesion that develops may occasionally be centrally positioned, the disorder typically progresses from a gradual thinning of the peripheral corneal stroma to the formation of a perforation prone gutter. Activated matrix metalloproteinase I (MMP-I or collagenase I), the enzyme that exhibits specificity for type I collagen, the major component of the corneal extracellular matrix, has long been implicated as a causative agent of PUK. ${ }^{12}$ The results of an early investigation indicated that this enzyme is secreted by limbal inflammatory cells and/or conjunctival epithelial cells lying adjacent to the corneal ulcers induced by rheumatoid arthritis. ${ }^{3}$ More recently it has been suggested that MMP-I is produced within the stroma of affected corneas, either by the corneal keratocytes themselves or by infiltrating macrophages. ${ }^{4} \mathrm{Al}-$ though treatment for PUK relies heavily upon long term systemic immunosuppressive therapy, ${ }^{5}$ such treatment may not prevent corneal perforation. In this event graft surgery to replace the lysed cornea may also fail presumably because of the continued existence of activated proteases and/or inflammatory cells within the host corneal matrix. Thus, despite the general agreement that corneal destruction is inflicted by MMP-I, there exists uncertainty with respect to the source of this enzyme, its activation mechanism, and whether other proteolytic enzymes are also involved in the initiation or maintenance of the diseased state. The primary aim of the current investigation was to characterise the MMPs specifically secreted by keratocytes of perforated PUK corneas and compare their activity profiles with those secreted by keratocytes of healthy corneas. In consideration of remedial therapies for PUK, the effects of possible MMP activity regulators were also investigated. These included prednisolone, because it is currently used, but sometimes ineffectually, to arrest disease progression, and the divalent cations $\mathrm{Cu}^{2+}$ and $\mathrm{Zn}^{2+}$, because all MMPs contain $\mathrm{Zn}^{2+}$ at their catalytic centre and require $\mathrm{Ca}^{2+}$ for activity. In addition to these investigations, the tears of patients suffering from rheumatoid arthritis were also assayed for MMP activity during periods of active PUK progression and periods of disease quiescence.

\section{Methods}

EXPERIMENTAL MATERIAL

\section{Corneas}

To serve as the experimental control, corneal tissue that was unsuitable for transplantation, because of minor endothelial defects, was
Accepted for publication 19 July 1999 
obtained from the Bristol CTS Eye Bank. Perforated corneal tissue from patients with chronic PUK was obtained from theatre immediately after graft surgery.

Tears

After applying $20 \mu \mathrm{l}$ of a sterile solution of saline $(0.9 \% \mathrm{w} / \mathrm{v})$ to the fornix of each eye, tear samples (approx 10-15 $\mu \mathrm{l}$ ), were collected from healthy individuals and rheumatoid patients with PUK, using $20 \mu \mathrm{l}$ glass capillary tubes. The clinical criteria that were used to assess the severity of the PUK in these patients are given below.

\section{Clinical signs of active PUK progression and resolution}

PUK severity relates to the degree of conjunctival inflammation, corneal thinning, and hyperaemia. The signs of active PUK are the formation of a gutter just inside the corneal limbus and considerable thinning of the cornea. While vascularisation is usually absent, there is surface staining with fluorescein dye and elevation of the conjunctiva. This often appears as a rolled edge alongside the ulcer. The signs of resolution of active inflammation include epithelialisation of the corneal surface and the formation of a superficial layer of fibrotic material beneath the epithelium. In addition, corneal vascularisation occurs, the conjunctiva flattens, and the hyperaemia resolves.

\section{TISSUE CULTURE}

Corneal keratocyte culture and maintenance

PUK corneas may contain proteolytic enzymes derived from inflammatory cells. Since the primary aim of this inquiry was to determine whether the MMPs secreted by the keratocytes of PUK corneas contributed to the destruction of their extracellular matrices, confluent keratocyte cultures were established from normal and PUK corneas as described below.

Epithelial cell layers were stripped from the underlying corneal stroma before dicing this tissue in a small quantity of Dulbecco's MEM growth medium (Gibco) supplemented with fetal calf serum (FCS, $10 \% \mathrm{v} / \mathrm{v})$, glutamine (Gibco), and an antibiotic-antimycotic mixture (Sigma). The explants were seeded into $25 \mathrm{ml}$ culture flasks. Once cell growth was established, to achieve uniform confluent cultures, the keratocytes were trypsinised, pelleted by centrifugation, resuspended in 4-6 $\mathrm{ml}$ fresh medium and divided between 4-6 culture flasks. These flasks were incubated for 1 hour at $37^{\circ} \mathrm{C}$ to allow the explants to adhere, then more medium ( $2 \mathrm{ml}$ ), was added. This was changed every 3-4 days. On achieving confluence, the FCS was omitted from the culture media for intermittent periods of 4 days. These media samples were then collected. Aliquots were removed and stored at $-80^{\circ} \mathrm{C}$ for direct analysis of the secreted gelatinase activities. The protein fractions of the rest of the media were obtained by $\left(\mathrm{NH}_{4}\right)_{2} \mathrm{SO}_{4}$ precipitation.
Epithelial cell culture

Ocular toxicity studies are frequently carried out using corneal epithelial cell cultures. As an addendum to the experiments in which the effects of $\mathrm{Zn}^{2+}$ and $\mathrm{Cu}^{2+}$ on keratocyte MMP secretion and viability were investigated, the effects of these metal ions on epithelial cell proliferation and viability were also assessed. The cultures were prepared by plating out corneal explants, taken from anterior limbal regions of normal corneas, in small petri dishes (5 $\mathrm{cm}$ diameter) and incubating them in RPM-I 1640 culture medium containing 5\% $\mathrm{v} / \mathrm{v}$ FCS. Once epithelial cell growth was established ( $\sim 7$ days) the explants were removed to reduce the possibility of fibroblast proliferation The media were changed every 3-4 days. When near confluent, the cells were used for experimentation.

PREPARATION OF PROTEIN SAMPLES FOR MMP ANALYSIS

Keratocyte secreted proteins were harvested by $\left(\mathrm{NH}_{4}\right)_{2} \mathrm{SO}_{4}$ precipitation of their serum free culture media. The $\left(\mathrm{NH}_{4}\right)_{2} \mathrm{SO}_{4}$ was added as a saturated solution in $10 \mathrm{mM}$ potassium phosphate buffer, $\mathrm{pH}$ 7.4, to a final concentration of $70 \%(\mathrm{w} / \mathrm{v})$. The protein precipitates produced after a minimum period of 6 hours at $4^{\circ} \mathrm{C}$ were pelleted by centrifugation at $20000 \mathrm{~g}$ for 30 minutes at $4^{\circ} \mathrm{C}$, redissolved in $10 \mathrm{mM}$ phosphate buffer, $\mathrm{pH} 7.4$, containing $0.2 \mathrm{M}$ $\mathrm{NaCl}$ and $10 \%(\mathrm{v} / \mathrm{v})$ glycerol and stored at $-80^{\circ} \mathrm{C}$ (long term) or $-20^{\circ} \mathrm{C}$ (short term).

The proteins present in tears were not concentrated. Tear solutions collected from normal subjects and patients with PUK were either assayed directly for gelatinase activity, or after storage at $-80^{\circ} \mathrm{C}$.

MMP DETECTION AND ACTIVITY ASSAYS

It is known that the MMPs account for over $95 \%$ of the proteolytic activity secreted by normal keratocytes. ${ }^{6}$ In vivo, these enzymes usually exist in an inactive form, either as the proenzyme, or as the activated enzyme bound to tissue inhibitor of metalloproteinase (TIMP). To cause tissue damage, they must exist for a finite period in an activated form, free of TIMP. The following methods were used to characterise, quantify, and assess the activity status of the ocular MMPs of healthy individuals and patients with PUK.

\section{Acyl transferase activity}

Since all proteases will catalyse acyl transfer independently of peptidase activity, total MMP (active and inactive) was estimated from the kinetics of liberation of 4-nitrophenol from 4-nitrophenyl acetate as described previously. ${ }^{6}$

Substrate-polyacrylamide gel electrophoresis Gelatinase activities were separated and visualised by electrophoresis on SDSpolyacrylamide gels $(8.5 \%)$ containing gelatin (1 $\mathrm{mg} / \mathrm{ml})$, as described by Unemori and Werb. ${ }^{7}$ The sample solutions contained SDS $(1 \% \mathrm{w} / \mathrm{v})$ and glycerol $(10 \% \mathrm{v} / \mathrm{v})$, and were applied to the gels without boiling or reduction. Unless otherwise stated, for characterisa- 
tion of the keratocyte secreted gelatinases, equivalent volumes of the culture media of confluent cultures were applied to the gels. All other samples analysed by this method were of similar protein concentration $(7 \mu \mathrm{g} / \mathrm{lane})$. Protein standards of known molecular weight $\left(M_{\mathrm{r}}\right.$ 220 000-22 000, Sigma Chem Co), were also included on each gel. After staining the gels with Coomassie blue, at applied concentrations of approximately $120 \mu \mathrm{g} / \mathrm{ml}$, these proteins stained darker than the gelatin that was included in the polyacrylamide gel matrix.

\section{Collagen hydrolysis}

The in vivo state of activation of the various enzyme preparations was assessed by their ability to hydrolyse standard collagen samples. Types I, II, III, IV, and V collagens were dissolved in $10 \mathrm{mM}$ acetic acid $(4 \mathrm{mg} / \mathrm{ml})$, then neutralised with an equal volume of $0.1 \mathrm{M}$ TRIS $\mathrm{HCl}, \mathrm{pH} 7.8$ containing $5 \mathrm{mM} \mathrm{CaCl}_{2}$. Denatured type I collagen (gelatin) was obtained by heating a sample of the type I collagen solution at $60^{\circ} \mathrm{C}$ for 20 minutes. All collagens were then incubated with and without the various enzyme preparations, in the same buffer, at $37^{\circ} \mathrm{C}$. Aliquots were removed with time (0-18 hours), and added to an equal volume of the polyacrylamide gel electrophoresis (PAGE) sample buffer ${ }^{8}$ containing SDS (2\% $\mathrm{v} / \mathrm{v})$ and mercaptoethanol (5\%). After heating these samples at $60^{\circ} \mathrm{C}$ for 20 minutes, they were analysed on SDS polyacrylamide gels $(10 \% \mathrm{w} / \mathrm{v})$ as described by Laemmli. ${ }^{8}$

PROTEIN ESTIMATION

Protein concentration was estimated spectrophotometrically from the relation $\mathrm{OD}_{225} 9.18$ $=1.0 \mathrm{mg} / \mathrm{ml}^{9}$ using quartz cuvettes of $1 \mathrm{~cm}$ path length but reduced volume. Sample protein preparations were diluted with distilled water. The solutions in which the proteins were dissolved were similarly diluted with distilled water, and used as blanks.

INHIBITION STUDIES

Effect of prednisolone, $\mathrm{Zn}^{2+}$, and $\mathrm{Cu}^{2+}$ on

keratocyte MMP production and viability

For this study, the chosen experimental concentrations of prednisolone and the metal ions were effectively determined by their solubility in aqueous solution. They were dissolved in serum-free MEM culture medium at concentrations ranging from $0-1 \mathrm{mM}$ and $0-2 \mathrm{mM}$ respectively, before filter sterilising. The media solutions of prednisolone, $\mathrm{Zn}^{2+}$, and $\mathrm{Cu}^{2+}$ were then added, at increasing concentration, to a set of normal and a set of PUK keratocyte cultures. Each set contained keratocytes derived from the same cornea. Their culture media was harvested for MMP analysis after 4 days' incubation at $37^{\circ} \mathrm{C}$. The experiment was subsequently repeated using cultures derived from different normal and PUK corneas.

Effect of $\mathrm{Cu}^{2+}$ and $\mathrm{Zn}^{2+}$ on the growth kinetics of epithelial cell cultures

Near confluent cultures of epithelial cells were trypsinised, centrifuged at $1500 \mathrm{rpm}$ for 3 minutes, resuspended in the RPM-I 1640 cul- ture medium containing 5\% (v/v) FCS and counted with a haemocytometer. The cells were then pipetted into the wells of 96 well plates $(50 \mu \mathrm{l}$ aliquots of medium containing $2-5 \times 10^{3}$ cells). After 2 hours' incubation at $37^{\circ} \mathrm{C}$, a further $150 \mu \mathrm{l}$ of this medium containing $\mathrm{ZnCl}_{2}(25 \mu \mathrm{m}-50 \mu \mathrm{mM}$ concentration range) or $\mathrm{CuCl}_{2}(25 \mu \mathrm{m}-2 \mathrm{mM}$ concentration range) were added to each well. Each cation concentration was assayed in quadruplicate. Five replica plates were prepared and incubated at $37^{\circ} \mathrm{C}$ for a maximum period of 14 days. Viable cell densities were estimated at days $1,2,4,7$, and 14 by the hexominidase assay method of Landegren et $a l^{10}$ described below.

The hexominidase substrate, $\mathrm{p}$-nitrophenyl$N$-acetyl $\beta$-D glucosaminide, was dissolved in $0.1 \mathrm{M}$ citrate buffer, $\mathrm{pH} 5.0$ containing $0.25 \%$ $(\mathrm{v} / \mathrm{v})$ Triton X-100 at a concentration of 7.5 $\mathrm{mM}$. This was added, in $50 \mu \mathrm{l}$ aliquots, to cells washed free of culture medium. After an incubation period of 2 hours at $37^{\circ} \mathrm{C}$, the reactions were stopped with $150 \mathrm{mM}$ glycine EDTA (ethylenediamine tetra-acetic acid) buffer, $\mathrm{pH}$ 10.4. Colour development was monitored using a microplate reader (Dynatech MR 5000) fitted with $410 \mathrm{~nm}$ filter. Cell densities were read against a standard curve, constructed from the results obtained from serially diluted cell suspensions of known density.

\section{Results}

CHARACTERISATION OF THE GELATINASE ACTIVITIES SECRETED BY KERATOCYTES CULTURED FROM NORMAL AND PUK CORNEAS The gelatinase activities secreted by confluent cultures of keratocytes derived from a minimum number of 15 normal adult (45-78 years) and 10 PUK (68-82 years) corneas have been analysed by substrate polyacrylamide gel electrophoresis. Typical activity profiles of gelatinases secreted by normal and PUK keratocytes are shown in Figure 1. As expected from previously published data, ${ }^{6}{ }^{11}$ the major gelatinase activities detected in all samples of the keratocyte culture media could be ascribed to MMP-2. In the case of the normal keratocytes, this enzyme was represented by the $M_{\mathrm{r}} 66000$ form predominantly. Most samples analysed using a Biorad GS-690 imaging

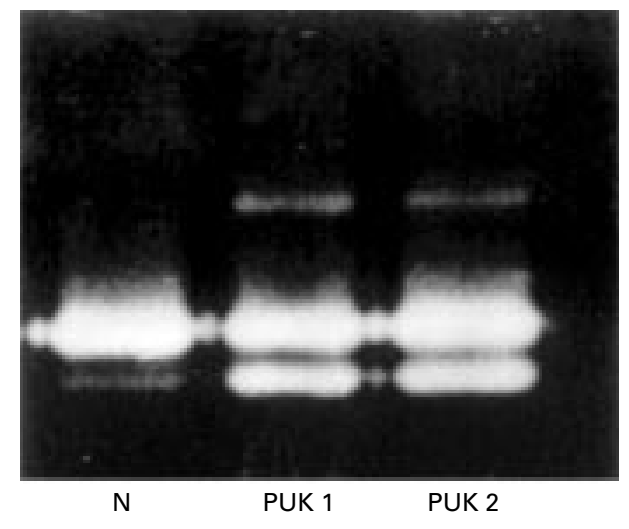

Figure 1 Characteristic zymographic activity profiles of the $M M P-2$ secreted by keratocytes cultured from normal and perforated PUK corneas. 


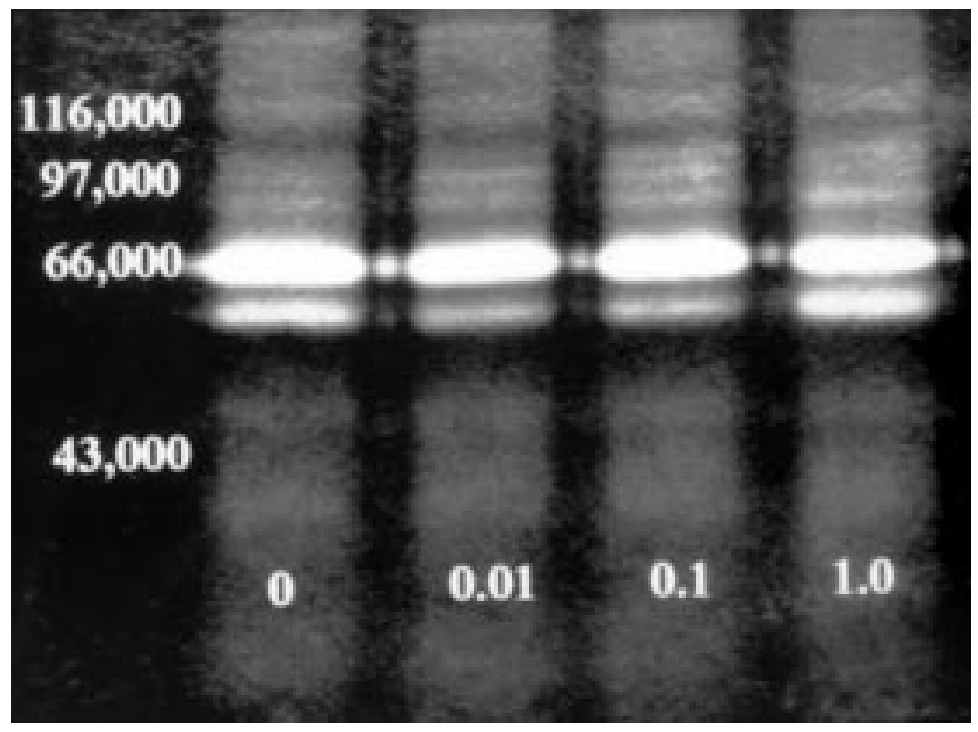

Figure 2 Zymographic analysis of the MMP-2 activities secreted by PUK corneal keratocytes cultured in serum free medium containing prednisolone $(0,0.01,0.10$, and 1.0 $m M$ ) for 4 days.

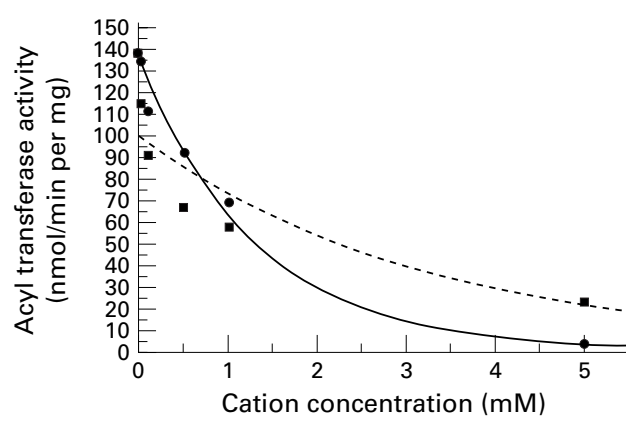

Figure 3 Kinetics of inhibition of acyl transferase activity of corneal $M M P-2$ by $\mathrm{Cu}^{2+}(\bullet)$ and $\mathrm{Zn}^{2+}(\mathbf{\bullet})$.

$(0,0.01,0.1$, and $1.0 \mathrm{mM})$ before harvesting for secreted MMP analysis. This procedure was repeated over a period of 6 weeks. During this time there was no observable change in the zymographic activities of the gelatinases secreted by either the normal or PUK cultures. Representative profiles of the latter are shown in Figure 2.

densitometer gave readings of less than $5 \%$ for the proportion of the total gelatinase activity represented by the $M_{\mathrm{r}} 62000$ form of MMP-2 on SDS-gelatin polyacrylamide gels. (4.7 (SE $2.6) ; n=7)$. In the case of PUK keratocytes, the $M_{\mathrm{r}} 62000$ form of MMP-2 was much more apparent, representing between $28-45 \%$ of the total activity visualised.

The concentrated protein fractions of the media of several of the PUK keratocyte cultures were subsequently assayed against type I (native and denatured) and type IV collagen. Despite the obvious presence of the MMP-2 activity of $M_{\mathrm{r}} 62000$ in the PUK keratocyte secreted protein preparations, there was no detectable degradation of any of these collagens after an incubation period of 18 hours at $37^{\circ} \mathrm{C}$ (data not shown).

KERATOCYTE SECRETED MMP INHIBITION STUDIES Prednisolone

Because systemic prednisolone treatment can be an effective method of curtailing the progression of PUK, experiments were carried out to determine whether this steroid could directly affect corneal MMP activity or production.

To assess the effect of prednisolone on MMP activity itself, this steroid was added, within the limits of its solubility in aqueous solution $(0-2.5 \mathrm{mM})$ to the assay buffers used to measure acyl transferase activity and develop the zymographic gelatinase activities. The data obtained by assaying the various keratocyte secreted protein preparations in the absence and presence of prednisolone are not shown, but indicated that this steroid has no effect on MMP acyl transferase activity or zymographic peptidase activity.

To assess the effects of prednisolone on MMP production, on separate occasions two different sets of normal and two different sets of PUK keratocyte cultures were incubated for 3 days in complete media then for 4 days in serum free medium containing prednisolone

\section{$\mathrm{Cu}^{2+}$ and $\mathrm{Zn}^{2+}$ cations}

All MMPs contain $\mathrm{Zn}^{2+}$ at their catalytic centre and require $\mathrm{Ca}^{2+}$ for stabilising the activated form of the enzyme. Therefore, in the expectation that other divalent cations would inhibit corneal keratocyte MMP acyl transferase and peptidase activities were compared. These metal ions were included in the respective assay buffers at concentrations ranging from $0-5$ $\mathrm{mM}$. The kinetics of inhibition of the acyl transferase activity of the MMP secreted by normal corneal keratocytes by $\mathrm{Cu}^{2+}$ and $\mathrm{Zn}^{2+}$ are shown in Figure 3. With respect to $\mathrm{Cu}^{2+}$, the measured decrease in reaction rate was a straightforward exponential function of cation 0.999). This was not the case for $\mathrm{Zn}^{2+}$; the kinetics were complex and appeared to be composed of two components. This may suggest that $\mathrm{Zn}^{2+}$ both interacts with the enzyme bound catalytic $\mathrm{Zn}^{2+}$ through the formation of zinc monohydroxide that reversibly bridges the catalytic zinc to a side chain in the enzyme's active site, ${ }^{12}$ and competes with the conformationally important $\mathrm{Ca}^{2+}$ that binds to a different domain of the protein.

With respect to the effect of $\mathrm{Cu}^{2+}$ and $\mathrm{Zn}^{2+}$ on MMP peptidase activity, both metal ions completely inhibited the zymographic gelatinase activities secreted by normal and PUK corneal keratocytes at concentrations exceeding $1.0 \mathrm{mM}$. These data are not shown but, because of the observed inhibition of MMP activity in vitro, the effects of these metal ions on MMP production and on corneal keratocyte and epithelial cell viability were also investigated. They were included, at varying concentration, in the cell culture media.

The result of incubating keratocyte cultures in serum free medium in the presence of $\mathrm{Cu}^{2+}$ ( $1 \mathrm{mM}$ ) for 4 days was that they produced enzyme which, when freed of this metal ion by ultrafiltration, hydrolysed type IV but not types I, III, or V collagen (Fig 4). Analysis of these activated enzyme preparations on substrate MMP activity, the effects of $\mathrm{Cu}^{2+}$ and $\mathrm{Zn}^{2+}$ on concentration (relative rate $=\mathrm{e}^{-0.76\left[\mathrm{Cu}^{2+}\right]}, \rho=$ 

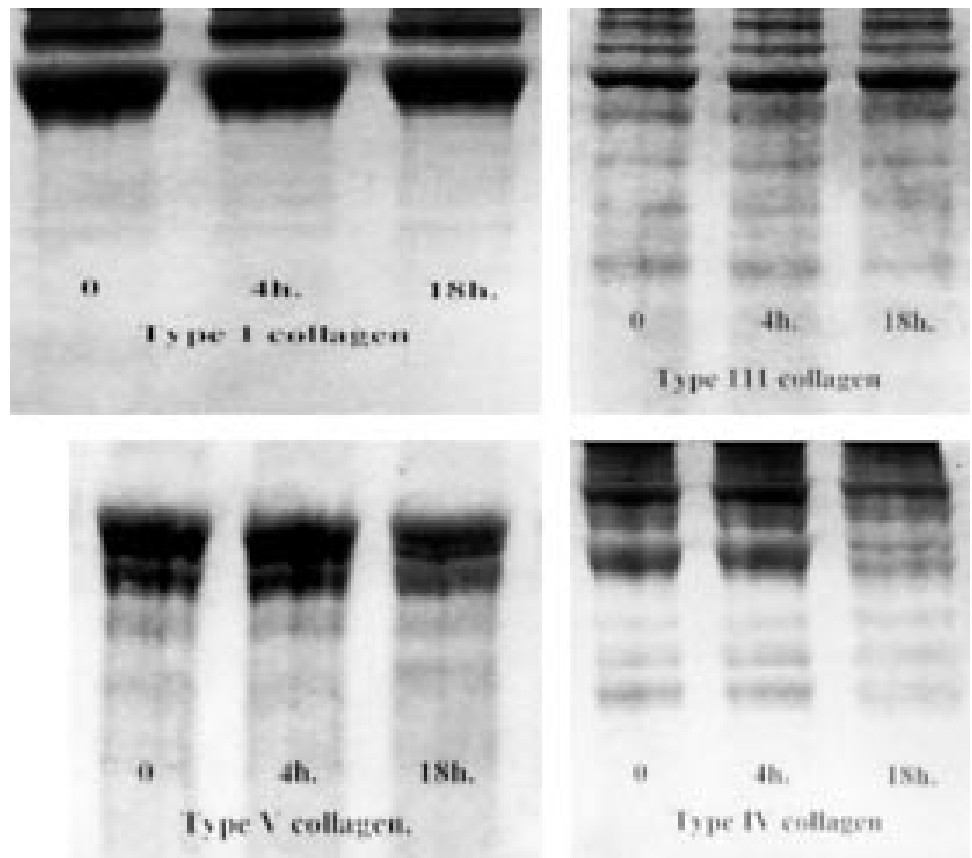

Figure 4 SDS-PAGE analysis of types I, III, IV, and V collagens incubated with aliquots of a protease preparation obtained from normal keratocyte cultures maintained in serum free medium in the presence of $\mathrm{Cu}^{2+}(1 \mathrm{mM})$.

polyacrylamide gels did not yield discrete bands of gelatinase activity: representative zymographic activity profiles of the gelatinases present in the culture media of normal keratocytes incubated with $\mathrm{Cu}^{2+}(0-2 \mathrm{mM})$ are shown in Figure 5A. The absence of the $M_{\mathrm{r}}$ 66000 and $M_{\mathrm{r}} 62000$ gelatinase activities in the profiles obtained when the $\mathrm{Cu}^{2+}$ concentrations were 1 or $2 \mathrm{mM}$ was very apparent and in these cases, the regions of maximum gelatinase activity occurred between $M_{\mathrm{r}} 40000$ and 50000 and at approximately $M_{\mathrm{r}}^{\mathrm{r}} 20000$.

The $\mathrm{Cu}^{2+}$ induced production of activated gelatinase was apparently specific to keratocytes. Whereas epithelial cell growth was unaffected by the inclusion of $\mathrm{Cu}^{2+}(<2 \mathrm{mM})$ in their culture media (data not shown), the physiological consequence of maintaining keratocytes in the presence of $\mathrm{Cu}^{2+}(>1 \mathrm{mM})$ was that they became detached from their culture flasks and eventually died (Table 1). The same phenomenon was observed when the $\mathrm{Cu}^{2+}$ induced activated gelatinase of keratocytes, prepared by ultrafiltration, was introduced into flasks containing epithelial cell cultures, but not when added to keratocyte cultures established without exposure to $\mathrm{Cu}^{2+}$.

By contrast with the observed effects of $\mathrm{Cu}^{2+}$ on cultured keratocyte viability and gelatinase production, $\mathrm{Zn}^{2+}(>1 \mathrm{mM})$ inhibited MMP-2 production by keratocytes (Fig $5 \mathrm{~B}$ ) and the expected reappearance of the zymographic gelatinase activity did not occur, even after a period of 4 weeks in which the cells were maintained in the absence of $\mathrm{Zn}^{2+}$ in medium containing FCS. At the end of this period the cells appeared to be viable as judged by staining with trypan blue. Furthermore, studies in which the effect of $\mathrm{Zn}^{2+}$ on epithelial cells was assessed indicated that this cation was non-toxic to epithelial cells at the concentra-
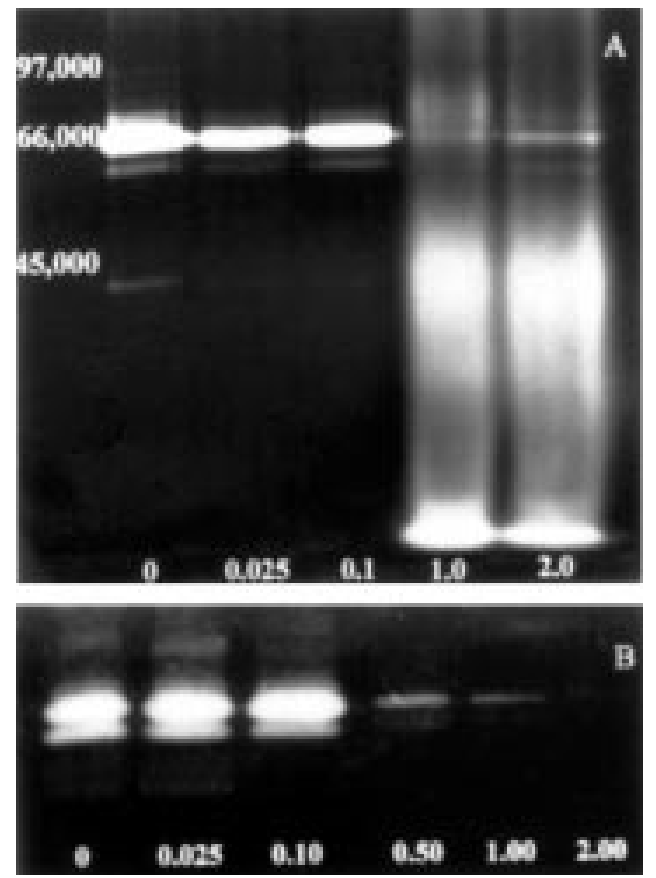

Figure 5 Zymographic gelatinase activity profile of a normal corneal keratocyte culture maintained in serum free medium containing $\mathrm{Cu}^{2+}(A)$, and a PUK keratocyte culture maintained in serum free medium containing $\mathrm{Zn}^{2+}$ (B). In both cases the metal ion concentration ranged from 0 to $2.0 \mathrm{mM}$

tion that inhibited MMP-2 production. Indeed, at concentrations below $1 \mathrm{mM}$, this metal ion appeared to stimulate epithelial cell proliferation (Table 2).

DETECTION AND CHARACTERISATION OF GELATINASE ACTIVITIES IN TEARS OF PATIENTS WITH PUK

For this investigation, tear samples were collected from four healthy individuals and seven patients whose severity of PUK was clinically assessed at the time of tear sample collection according to the degree of conjunctival inflammation and corneal thinning, but independently of medication. These were ana-

Table 1 Effect of $\mathrm{Cu}^{2+}$ on keratocyte viability and total protease secretion over an incubation period of 4 days

\begin{tabular}{|c|c|c|}
\hline $\begin{array}{l}\mathrm{Cu}^{2+} \\
\text { concentration } \\
(\mathrm{mM})\end{array}$ & $\begin{array}{l}\text { No of dead cells } \\
\text { released into growth } \\
\text { medium of confluent } \\
\text { culture }\end{array}$ & $\begin{array}{l}\text { Acyl transferase } \\
\text { activity (nmol/min } \\
\text { per mg) }\end{array}$ \\
\hline 0 & $<1 \times 10^{3}$ & 20.4 \\
\hline 0.5 & $4 \times 10^{4}$ & 31.9 \\
\hline 1.0 & $12 \times 10^{4}$ & 28.3 \\
\hline
\end{tabular}

Table 2 Effect of $\mathrm{Zn}^{2+}$ on the growth kinetics of corneal epithelial cell cultures

\begin{tabular}{lllll}
\hline \multirow{5}{*}{\begin{tabular}{l}
$Z^{2+} \begin{array}{l}n^{2} \\
\text { concentration } \\
(m M)\end{array}$ \\
\cline { 2 - 5 }
\end{tabular}} & $\begin{array}{l}\text { Cell density }\left(\times 10^{5} \text { cell/ml }\right) \\
\text { period of } 14 \text { days }\end{array}$ & measured over $a$ \\
\cline { 2 - 5 } 0 & 0.55 & 0.48 & 1.17 & 18.40 \\
0.025 & 1.42 & 1.18 & 4.00 & 27.60 \\
0.10 & 1.14 & 1.16 & 2.00 & 27.20 \\
1.00 & 0.78 & 1.52 & 2.36 & 27.20 \\
5.00 & 0.56 & 1.16 & 2.32 & 25.00 \\
10.00 & 0.50 & 1.22 & 4.00 & 23.00 \\
25.00 & 0.28 & 0.56 & - & - \\
50.00 & 0.27 & 0.20 & - & - \\
\hline
\end{tabular}




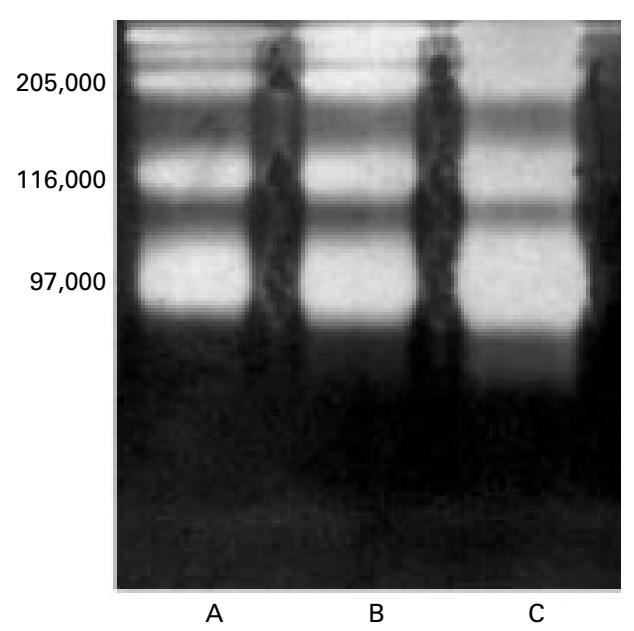

Figure 6 Zymographic characterisation of the gelatinase activities present in the tears of three rheumatoid patients $(A, B, C)$ with severe PUK.

lysed by substrate gel electrophoresis. The data obtained indicated that normal tears contain little or no MMP but those of patients with severe symptoms of PUK all contained several high molecular weight gelatinases of apparent $M_{\mathrm{r}} 92000-205000$ (Fig 6). The peptidase activities of all these enzymes exhibited $\mathrm{Ca}^{2+}$

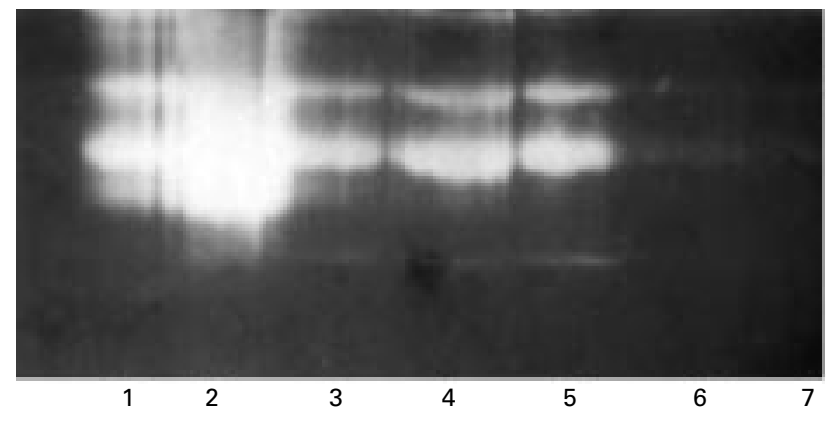

116,000

97,000

66,000

Figure 7 Zymographic analysis of the gelatinase activities present in the tears of rheumatoid patients with severe PUK (lane 2) and moderate PUK (lanes 1, 3, 4, 5), and in the tears of healthy subjects (lanes 6, 7).

Table 3 Evaluation of the relation between clinical assessment of PUK activity and gelatinase activity in tear secretions

\begin{tabular}{|c|c|c|c|c|c|}
\hline \multirow[b]{2}{*}{ Tear sampl } & & \multicolumn{2}{|c|}{ Clinical assessment } & \multirow[b]{2}{*}{$\begin{array}{l}\text { Acyltransferase activity } \\
\text { (nmol/min per mg) }\end{array}$} & \multirow{2}{*}{$\begin{array}{l}\text { Gelatinase B } \\
\text { activity. } \\
\text { (visualised) }\end{array}$} \\
\hline & & Corneal status & $\begin{array}{l}\text { Conjunctival } \\
\text { inflammation }\end{array}$ & & \\
\hline \multirow[t]{2}{*}{ PUK } & $1 \mathrm{R}$ & No thinning & + & 45 & + \\
\hline & $1 \mathrm{~L}$ & Perforation & ++++ & 107 & +++ \\
\hline \multirow[t]{2}{*}{ PUK } & $2 \mathrm{R}$ & Thinning & ++ & 80 & $+/-$ \\
\hline & $2 \mathrm{~L}$ & No thinning & + & 43 & $+/-$ \\
\hline \multirow[t]{2}{*}{ PUK } & $3 \mathrm{R}$ & Thinning & + & 45 & $+/-$ \\
\hline & $3 \mathrm{~L}$ & Thinning & + & 84 & + \\
\hline \multirow[t]{2}{*}{ PUK } & $4 \mathrm{R}$ & Thinning & ++ & 128 & + \\
\hline & $4 \mathrm{~L}$ & Thinning & + & 73 & $+/-$ \\
\hline PUK & $5 \mathrm{R}$ & Thinning & + & 23 & $+1-$ \\
\hline PUK & $6 \mathrm{R}$ & Perforation & ++++ & 112 & +++ \\
\hline \multirow[t]{2}{*}{ PUK } & $7 \mathrm{R}$ & Thinning & ++ & 113 & ++ \\
\hline & $7 \mathrm{~L}$ & Perforation & ++++ & 108 & +++ \\
\hline \multirow{2}{*}{ Normal } & $1 \mathrm{R}$ & Normal & - & 16 & - \\
\hline & $1 \mathrm{~L}$ & Normal & - & 12 & - \\
\hline \multirow[t]{2}{*}{ Normal } & $2 \mathrm{R}$ & Normal & - & 47 & - \\
\hline & $2 \mathrm{~L}$ & Normal & - & 24 & - \\
\hline \multirow[t]{2}{*}{ Normal } & $3 R$ & Normal & - & 29 & - \\
\hline & $3 \mathrm{~L}$ & Normal & - & 45 & - \\
\hline \multirow{2}{*}{ Normal } & $4 \mathrm{R}$ & Normal & - & 59 & - \\
\hline & $4 \mathrm{~L}$ & Normal & - & 60 & - \\
\hline
\end{tabular}

$\mathrm{R}=$ right eye; $\mathrm{L}=$ left eye. dependence and were totally inhibited by the cation chelator, EDTA at a concentration of 1 $\mathrm{mM}$, and by dithiothreitol ( $>2 \mathrm{mM})$, even after the removal of these compounds by ultrafiltration before analysis by substrate gel electrophoresis (data not shown).

These enzymes are, therefore, MMPs. The species of $M_{\mathrm{r}} 92000$ co-migrated with an authentic sample of MMP-9 of $M_{\mathrm{r}} 92000 .{ }^{13}$ The other higher $M_{\mathrm{r}}$ species are also believed to be MMP-9, but complexed with TIMP (A Newby, University of Bristol, personal communication). In common with the MMPs secreted by corneal keratocytes, the MMPs in the tears of patients with PUK exhibited no detectable activity when assayed against type I, type III, type IV, and type V collagen in vitro or when assayed zymographically in the presence of $\mathrm{Cu}^{2+}$ or $\mathrm{Zn}^{2+}$ at concentrations exceeding 1 $\mathrm{mM}$.

The quantity of proteolytic enzyme, including MMP-9, in tear secretions of patients with rheumatoid arthritis related to the clinical signs of advancing PUK, specifically the extent of conjunctival inflammation and corneal thinning in each eye of individual patients. The data obtained are given in Figure 7 and Table 3. From the latter, the mean (SE) values for the acyl transferase activities of proteolytic enzymes in tears of normal subjects and in tears of patients' eyes with mild, moderate, and severe PUK were calculated to be 36.5 (16) $\mathrm{nmol} / \mathrm{min}$ per $\mathrm{mg}(\mathrm{n}=8) ; 52(23) \mathrm{nmol} / \mathrm{min}$ per $\operatorname{mg}(\mathrm{n}=6) ; 107(61) \mathrm{nmol} / \mathrm{min}$ per $\mathrm{mg}(\mathrm{n}=3)$, and 109 (6) $\mathrm{nmol} / \mathrm{min}$ per $\mathrm{mg}(\mathrm{n}=3)$ respectively.

Statistically, the amount of proteolytic enzyme in the tears of patients' eyes with mild PUK was not significantly different from that in the tears of normal subjects (Student's $t$ test for unpaired data, $p>0.2$ ). This was not the case, however, for the amount of proteolytic enzyme in the tears of medium and heavily inflamed eyes of PUK patients. In these tear samples, though the quantities of proteolytic enzyme were not significantly different from each other $(p>0.2)$, they were significantly greater than that found in normal tears $(p$ values $<0.001$ ).

INDIVIDUAL CASE STUDIES

In addition to the tear samples documented in Table 3, others were periodically collected for

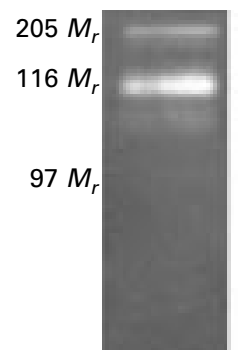

A

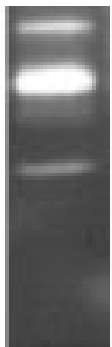

$\mathrm{B}$

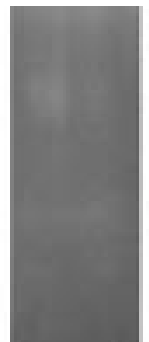

C

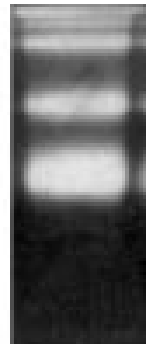

D
Figure 8 Zymographic analysis of the gelatinase activities in the tears of a patient with rheumatoid arthritis: $(A)$ on initial presentation with ocular complications; (B) after a further period of 4 weeks; $(C)$ after 4 weeks of treatment with prednisolone; (D) At time of corneal perforation. 
analysis from individual patients during the course of their treatment for PUK, in periods of exacerbation and remission. Representative zymographic activity profiles of the gelatinases present in the samples taken from one of these patients on initial presentation, during a subsequent period of quiescence brought about by systemic steroid therapy, and when the cornea finally perforated despite continuity of the systemic steroid treatment, are shown in Figure 8. From these data it was concluded that the gelatinase activity bands are most intense at the time of corneal perforation. During periods of quiescence, they become barely discernible.

\section{Discussion}

Peripheral ulcerative keratitis (PUK) is an ocular complication of rheumatoid arthritis. We have shown that disease progression correlates with the abnormal production of MMP-2 of $M_{\mathrm{r}} 62000$ in corneal stromal tissue and with the appearance of MMP-9 in tear secretions. Both these enzymes exhibit specificity for type IV basement membrane collagen. ${ }^{14}{ }^{15}$ Whereas the MMP-2 is secreted by the corneal keratocytes, the MMP-9 secretory cells have not as yet been identified. It is possible that they are of the lacrimal gland, conjunctival epithelium, or the corneal epithelium itself but it is equally likely that the producer cells are the invasive inflammatory cells (macrophages and neutrophils) that accumulate at the corneal limbus. ${ }^{13}{ }^{16}$ Whatever the source of MMP-9, the existence of this enzyme in tears is easily detected and quantified, and could be used as a sensitive monitor of PUK progression.

The possibility that the gelatinases (MMP-2 and MMP-9) may be involved in peripheral ulcerative keratitis has not been considered previously. Most reports concerned with the role of proteolytic enzymes in PUK have focused primarily on the stimulated production of interstitial collagenase (MMP-1) and/or an apparent reduction in the tissue concentration of its inactivating protein ligand, TIMP- $1 .{ }^{3}$ However, because of our observation that gelatinase production or overproduction correlated with clinical manifestations of PUK progression, we hypothesised that these enzymes, once activated, may initiate perforation by breaching the corneal basement membranes (epithelial cell and Descemet's). By hydrolysing newly synthesised, noncrosslinked interstitial collagens, they could also limit tissue repair and facilitate infiltration of inflammatory cells and their proteolytic enzymes (including the MMP that hydrolyses type 1 collagen) into the corneal stroma.

If the gelatinases are involved in PUK progression, the disease may not be arrested without inhibiting their activity or production. Data presented here and elsewhere ${ }^{6}$ have indicated that keratocyte secreted protein preparations that zymographically showed the $M_{\mathrm{r}}$ 66000 and $M_{\mathrm{r}} 62000$ activities of MMP-2 only contained no detectable gelatinase activity when assayed under native conditions. Neither was activated MMP-9 detected in tear secretions of patients with advanced disease symptoms. Although it is known that gelatinase acti- vation involves peptide cleavage ${ }^{17}$ that may be facilitated by the action of membrane bound or MT-MMPs, ${ }^{18}$ the pathogenic mechanism of activation of these enzymes may be different. In the case of PUK, corneal perforation is a localised event and almost always occurs at a site adjacent to invasive inflammatory cells. These inflammatory cells could produce enzymes or growth factors that locally stimulate the production of activated corneal gelatinases, including the MMP-9 produced by corneal epithelial cells. Through the subsequent action of these enzymes on type IV basement membrane collagen and other susceptible components of the corneal matrix, the penetration and diffusion of macrophages and inflammatory cell proteases, including the collagenase that hydrolyses the interstitial (types I and III) collagens, would be facilitated.

In agreement with an early report ${ }^{3}$ we consider that the inflammatory cells are likely to be the source of the enzymes that cause corneal perforation. Although it has been reported that MMP-1 is an endogenous corneal enzyme, secreted by stromal keratocytes ${ }^{19}{ }^{20}$ our data do not support this notion. The corneal keratocyte secreted protease preparations, which we have obtained and activated in various ways (that is, the inclusion of $\mathrm{Cu}^{2+}$ in the culture medium; protein fractionation following treatment with SDS; auto-oxidation and autocatalysis), readily hydrolyse type IV and type I collagen denatured by heating at $60^{\circ} \mathrm{C}$ for 20 minutes, but not native type $1 \mathrm{col}-$ lagen.

Successful management of corneal ulcerative keratitis frequently depends upon long term treatment with systemic immunosuppressants and one of the steroids commonly employed for this is prednisolone. During periods of quiescence achieved through its administration, we have found that the gelatinases present in patients' tears also regress. However, because of the observation that prednisolone had no direct effect upon MMP-2 activity or production by corneal keratocytes, we concluded that steroid treatment may suppress the accumulation of inflammatory cells at the corneal limbus but can offer no immediate protection for corneas in imminent danger of perforating.

Although both $\mathrm{Cu}^{2+}$ and $\mathrm{Zn}^{2+}$ were shown to inhibit both the acyl transferase activity and peptidase activities of MMP-2, the effects of these cations on MMP-2 production and/or secretion by corneal keratocytes were, however, unexpectedly quite different and occurred at concentrations that were non-toxic to the growth of epithelial cell cultures (between 1 and $2 \mathrm{mM}$ ).

The inclusion of $\mathrm{Cu}^{2+}(1-2 \mathrm{mM})$ in serum free keratocyte culture media induced the secretion of activated MMPs that hydrolysed type IV and denatured type I collagen in vitro. The loss of the $M_{\mathrm{r}} 66000$ and 62000 forms of MMP-2 in the zymographic activity profiles of such enzyme preparations was very apparent and the regions of maximum gelatinase activity occurred between $M_{\mathrm{r}} 40000$ and 50000 and at approximately 20000 . These findings sug- 
gest that either MMP-2 production is inhibited by $\mathrm{Cu}^{2+}$ and that other lower $M_{\mathrm{r}}$ gelatinases of similar substrate specificity are produced, or that $\mathrm{Cu}^{2+}$ induces the production of truncated but activated forms of MMP-2. The latter of these possibilities is supported by our observation that MMP-2 preparations that exhibit only the $M_{\mathrm{r}} 66000$ and 62000 zymographic activities never contain detectable activity when assayed under native conditions and by numerous observations, including our own, that MMP-2 activation is always accompanied by the production of a lower molecular weight gelatinase activities ${ }^{21-24}$ and in particular, one of $M_{\mathrm{r}} 43000$. The $\mathrm{Cu}^{2+}$ induced production of activated gelatinase was apparently specific to keratocytes but the exposed cells also rounded up and detached from their matrix. Conceivably, the $\mathrm{Cu}^{2+}$ also disrupted keratocyte cell junctions for, although the isolated enzyme caused cultured epithelial cells to detach from their basal matrix presumably by disrupting their basement membranes, it had no effect upon other established keratocyte cultures.

By contrast with the effect of $\mathrm{Cu}^{2+}$ on MMP production, $\mathrm{Zn}^{2+}$, within the concentration range 1-2 $\mathrm{mM}$, apparently inhibited MMP production on a permanent basis. Because of this observation and the fact that $\mathrm{Zn}^{2+}$ also inhibited MMP-2 activity, it is proposed that this metal ion could be of great therapeutic value if suitably formulated for topical application.

In conclusion, the data presented in this paper indicate that ocular MMP production correlates with clinical signs of active peripheral ulcerative keratitis in patients with rheumatoid arthritis and therefore supports the possibility of their involvement in initiating and/or maintaining the disease. Because of the thermal and chemical stability of MMPs, the remedial therapy for peripheral ulcerative keratitis should include, in addition to systemic steroids, the use of specific MMP activity inhibitors or, more positively, compounds that directly inhibit MMP production and activation. Since we have shown that $\mathrm{Zn}^{2+}$ inhibits MMP-2 production by corneal keratocytes, it is suggested that this cation may be of therapeutic value for all corneal diseases that involve MMPs. Together with $\mathrm{Cu}^{2+}$ it may also be used to generate model culture systems in which the molecular events associated with MMP production and activation may be investigated.
We are very grateful to the National Eye Research Centre (NERC) for financial support.

1 Brown SI, Weller CA, Wasserman HE. Collagenolytic activty of alkali burned cornea. Arch. Ophthalmol 1969;81:3706.

2 Gordon JM, Baur EA, Eisen AZ. Collagenase in human cornea. Arch Ophthalmol 1980;98:341-5.

3 Eiferman RA, Carothers DJ, Yankeelov JA. Peripheral rheumatoid ulceration and evidence for conjunctival collagenase production. Am f Ophthalmol 1979;87:703-9.

4 Riley GP, Harrall RL, Watson PG, et al. Collagenase (MMP-1) and TIMP in destructive corneal disease associated with rheumatoid arthritis. Eye 1995;9:703-18.

5 Tauber J, de la Mazza MS, Hoang-Xuan T, et al. An analysis of therapeutic decision making regarding immunosuppressive chemotherapy for peripheral ulcerative keratitis. Cornea 1990;6:66-73.

6 Smith VA, Hoh HB, Littleton M, et al. Over-expression of a

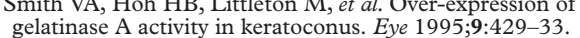

7 Unemori EN, Werb Z. Reorganisation of polymerised actin: a possible trigger for induction of procollagenase in a possible trigger for induction of procollagenase in fibroblasts cultured

1986;103:1021-31.
8 Laemmli UK. Cleavage of structural proteins during the assembly of the head of bacteriophage T4. Nature 1970;227:680-5

9 Hall BG, Hartl DL. Regulation of newly synthesised enzymes. II. The ebg repressor. Genetics 1975;81:427-35.

10 Landegren U. Measurement of cell numbers by means of the endogenous enzyme hexosaminidase: applications to detection of lymphokines and cell surface antigens. $f$ Immunol Methods 1984;67:379-88.

11 Brown B, Chwa M, Escobar M, et al. Characterisation of the major matrix degrading metalloproteinase of human major matrix degrading metalloproteinase of human Exp Eye Res 1991;52:5-16.

12 Larsen KS, Auld DS. Characterisation of an inhibitory metal-binding site in carboxypeptidase A. Biochemistry 1991;30:2613-18.

13 Matrisan LM. The matrix-degrading metalloproteinases. Bioessays 1992;14:455-63.

14 Liotta LA, Abe S, Gehron-Robey P, et al. Preferential digestion of basement membrane collagen by an enzyme derived from a metastatic murine tumor. Proc Natl Acad Sci USA 1979;76:2268-72.

15 Wilhelm SM, Collier IE, Marmer BL, et al. SV40 transformed human lung fibroblasts secrete a $92 \mathrm{kDa}$ type IV collagenase which is identical to that secreted by normal human macrophages. F Biol Chem 1989;2:17213-21.

16 Hibbs MS, Hasty KA, Seyer JM, et al. Biochemical and immunological characterisation of the secreted forms of human neutrophil elastase. F Biol Chem 1985;260:2493500 .

17 Crabbe T, Willenbrock F, Eaton D, et al. Biochemical characterisation of matrilysin. Activation conforms to the stepwise mechanisms proposed for other matrix metalloproteinases. Biochemistry 1992;31:8500-7.

18 Strongin AY, Marmer BL, Grant GA, et al. Plasma membrane-dependent activation of the $72-\mathrm{KDa}$ type IV collagenase is prevented by complex formation with TIMP-2. f Biol Chem 1993;268:14033-9.

9 Berman MB. Regulation of corneal fibroblast MMP-1 secretion by cytochalasins. Cornea 1994;13:51-7.

20 Berman M, Leary R, Gage J. Collagenase from corneal cell cultures and its modulation by phagocytosis. Invest Ophthalmol Vis Sci 1979;18:588-601.

21 Howard EW, Banda MJ. Binding of tissue inhibitor of metalloproteinases-2 to 2 distinct sites on human $72-\mathrm{KDa}$ gelatinase-identification of a stabilisation site $\mathcal{F} \mathrm{Biol}$ Chem 1991;266:17972-7.

22 Howard EW, Bullen EC, Banda MJ. Regulation of the autoactivation of human $72 \mathrm{KDa}$ progelatinase by tissue autoactivation of human $72 \mathrm{KDa}$ progelatinase by tissue inhibitor $13064-9$.

23 Fini ME, Yue YJT, Sugar J. Collagenolytic/gelatinolytic metalloproteinases in normal and keratoconus corneas. Curr Eye Res 1992;11:849-62.

24 Brown DJ, Chwa MM, Opbroek AJ, et al. Keratoconus corneas;Increased gelatinolytic activity appears after modification of inhibitors. Curr Eye Res 1993;12:571-81. 